\title{
Comparision of Effect of Lacrimal Sac Massage And Lacrimal Sac Massgae with Topical Antibiotic in Congenital Nasolacrimal Duct Obstruction
}

\author{
${ }^{1}$ Dr. Jitendra Kumar, ${ }^{2}$ Dr.Vijay Pratap Singh, ${ }^{3}$ Dr. Preeti Chaubey, \\ ${ }^{4}$ Dr. Amit Verma ${ }^{4}$ \\ ${ }^{I}$ Associate Professor, Department Of Ophthalmology, Maharani Laxmi Bai Medical College, Jhansi, UP, India \\ ${ }^{2}, 3,4$ Junior Resident, Department Of Ophthalmology, Maharani Laxmi Bai Medical College, Jhansi, UP, India \\ 3Junior
}

\begin{abstract}
:
Purpose: To compare the success rate of lacrimal sac massage and lacrimal sac massage with topical antibiotic (Tobramycin) in congenital nasolacrimal duct obstruction (CNLDO) in infant.

Method: 60 patients were taken, aged from 2 to 12 months diagnosed with CNDLO (from Sept. 2015 to Dec. 2016) were included and divided into 2 equal groups;

Group 1 advised for lacrimal sac massage only and

Group 2-advised for lacrimal sac massage with topical antibiotic. Patient was followed up at regular intervals upto three months. Successful outcome was documented as complete remission of symptoms in subsequent visits following the conservative therepies.

Results: Overall success rate of Group 1 (advised for lacrimal massage without topical antibiotic) was $80 \%$ and Success rate of Group-2 (advised for lacrimal sac massage with topical antibiotic) was $90 \%$.

Conclusion:Lacrimal sac massage with topical antibiotic is more effective conservative treatment for CNDLO than lacrimal massage alone.
\end{abstract}

Keywords: $C N L D O$, Lacrimal sac massage, Nasolacrimal duct.

\section{Introduction}

Congenital nasolacrimal duct obstruction (CNLDO) is the most common cause of epiphora in infants ${ }^{1,2}$ which may lead to infections, such as dacryocystitis, orbital cellulitis and bacterial conjunctivitis. A delay in the maturation of the lacrimal system where it enters the nose, results in a persistent membranous obstruction at the valve of Hasner is the cause for nasolacrimal duct obstruction in infants.Resolution of nasolacrimal duct obstruction without surgery ranges from $32 \%$ to $95 \%$ by 13 months of age. ${ }^{3-7} \mathrm{~A}$ wait-and-see policy accompanied by conservative therapies is one of the best options for congenital nasolacrimal duct obstruction in the first year of life. Lacrimal sac massage is usually performed as a conservative therapy for congenital nasolacrimal duct obstruction. Antibiotic eye drops are sometimes used in conjunction with conservative therapy when CNLDO is associated with mucopurulent discharge.Crigler was the first to describe a technique of applying a pressure over nasolacrimal sac area to manage congenital nasolacrimal duct obstruction in infants. The gentle pressure over the nasolacrimal sac area increases hydrostatic pressure within the lacrimal system which will subsequently help in resolution by rupturing the membranous obstruction at the distal end of nasolacrimal duct. The technique is being named as Crigler massage ${ }^{8}$.

\section{Material And Method}

A total of 60 infants with CNLDO, were included in this study conducted in the Department of Ophthalmology, Maharani LaxmiBai Medical College, Jhansi, Uttar Pradesh, India over a period of 15 months from Sept. 2015 to Dec. 2016. The procedures followed were in accordance with the ethical standards committee on human experimentation (institutional or regional) and with the Helsinki Declaration of 1975, as revised in 2000. The necessary permission from the Ethical and Research Committee was obtained for the study. In this study total 43 infant Included, who had diagnosed as a case of congenital nasolacrimal duct obstruction(CNLDO) which was confirmed by history, sign, symptoms, regurgitation test, dye disappearance test and local examination including slit lamp examination. and divided into two groups;

Group-1: Advised for lacrimal sac massage and regular follow up at every 15 days.

Group-2: Advised for lacrimal sacmassage with topical tobramycin antibiotic eye drop 1drop 4 times daily for 2 weeks and regular follow up at every 15 days. 
History

The parents will usually give a history of the child exhibiting unilateral or bilateral tearing. Other symptoms include crusting, mucoid or mucopurulent discharge and redness. The lashes may stick together in the morning or after the child takes a nap. Tearing may be aggravated by upper respiratory tract infections or with exposure to wind or cold

\section{Examination}

Any obvious crusting, redness or swelling of the lids is noted. The tear meniscus may be higher in the eye with CNLDO. Lid malpositions like ectropion, entropion or epiblepharon should be observed. Any facial abnormalities should be noted. Puncta should be inspected to rule out stenosis. Corneal clarity should be evaluated and the corneal diameter measured. Pressure over the lacrimal sac may discharge mucopurulent material into the lacrimal lake and is confirmatory. A dye disappearance test can be performed. After instilling a topical anesthetic, a drop of $2 \%$ fluorescein dye is instilled into the conjunctival cul-de-sac. Excess fluorescein is wiped away. After 5 minutes, the eyes are inspected for residual fluorescein with the cobalt blue light filter on the slit lamp opened wide. Failure to clear away the excess fluorescein is indicative of CNLDO.

Though it is widely known that massage of the nasolacrimal system relieves many congenital NLDobstructions during early infancy, the correct techniqueof massage is not properly understood by most parentsresulting in a high failure rate and need for probing. Massage of the lacrimal sac in a downward motion can exert hydrostatic pressure on the lower end of the lacrimal duct. This helps with drainage and, in the case of a minor blockage,may open the obstruction. This type of massage has been found by Kushner to be more effective in treating CNLDO than gentle pressure over the sac to express pus from the punctum, or no massage at all. Massage should be carried out four times a day, 5-10 strokes each time?

Technique of hydrostatic office sac massage: Parents were instructed not to empty the sac 1 day before visiting the OPD. While performing the office sac massage, place the tip of the index finger over at the inner canthus pressed in such a way that it presses the puncta and canaliculi which blocks the reflux of secretions through the puncta into the conjunctival sac after which it is pressed firmly medially and downwards to increase the hydrostatic pressure within the NLD which results in a feeling of give way along with a snapsound which indicates an effective massage. Drops were instilled by the parents for two weeks. Any other complication associated with congenital nasolacrimal duct obstruction, excluded from the study.

\section{Results}

In this study we found the overall success rate of Group 1 which advised for lacrimal massage without topical antibiotic was $80 \%$ (table.1) and success rate of Group-2which advised for lacrimal sac massage with topical antibiotic was $90 \%$ (table.1), and $15 \%$ patients advised for lacrimal probing.

Table-1

\begin{tabular}{|l|c|c|}
\hline & $\begin{array}{c}\text { No. of patients advised for lacrimal } \\
\text { sac massage (30) }\end{array}$ & $\begin{array}{c}\text { No. of patients advised for } \\
\text { Lacrimal sac massage with } \\
\text { topical antibiotic (30) }\end{array}$ \\
\hline $\begin{array}{l}\text { No. of patients had Complete } \\
\text { remission of the symptoms. }\end{array}$ & 24 & 27 \\
\hline $\begin{array}{l}\text { No. of patients advised for } \\
\text { probing }\end{array}$ & 06 & 03 \\
\hline Percentage of success & $80 \%$ & $90 \%$ \\
\hline
\end{tabular}

\section{Figure-1}

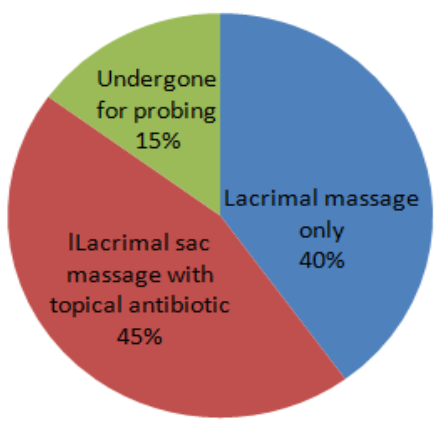




\section{Discussion}

In our study out of 60,51 patients $(85 \%)$ were cured by nasolacrimal duct massaging with and without topical antibiotic and out of $60,9 \operatorname{cases}(15 \%)$ needed lacrimal probing.Nazaullah khan et al $(2006){ }^{10}$ reported success rate of $83.2 \%$ of CNLDO by nasolacrimal duct massaging. Study done by QasemHammory et al $(2010)^{11}$ reported success rate of $82.5 \%$ of CNLDO by nasolacrimal duct massaging.In previous studies, lacrimal sac massage has been shown to have a success rate ranging from $28 \%$ to $95 \%$. We also found that children less than 12 month of age, experienced comparatively better success with sac massage compare to older children.The presence of mucoid fluid on regurgitation on pressure over lacrimal sac area, is suggestive of repeated or chronic inflamation of sac, which would likely cause higher failure rate of lacrimal massage. Few other factor that favors the failure rate of lacrimal massage in our study, as like low socio-economic status, parents unawareness about lacrimal massage,supra added infaction, poor hygiene, preterm birth etc.

\section{Conclusion}

Nasolacrimal duct probing is the treatment of choice for congenital nasolacrimal duct obstructionbut in this study we can see that, topical antibiotic increases the success rate of lacrimal sac massage.Lacrimal sac massage with topical antibiotic is more effective conservative treatment for CNDLO than lacrimal massage alone.

\section{References}

[1]. Young JD, MacEwen CJ. Managing congenital lacrimal obstruction in general practice. BMJ 1997;315:293-96

[2]. Kapadia MK, Freitag SK, Woog JJ. Evaluation and management of congenital nasolacrimal duct obstruction. OtolaryngolClin North Am 2006;39:959-77.

[3]. Shuman T, Gonzales C, Mazow ML. Treatment of congenital nasolacrimal duct obstruction. Am orthoptic J 1999;49:163-8.

[4]. Petersen RA, Rom RM. The natural course of congenital nasolacrimal duct. J pediatrophthalmol strabismus 1978;15:246-50.

[5]. Nelson LB, Calhoun JH, Menduke H. Medical management of congenital nasolacrimal duct obstruction. Ophthalmology 1985;92:1187-90.

[6]. Paul TO. Medical management of congenital nasolacrimal duct obstruction. J pediatrophthalmol strabismus 1985; 22:68-70.

[7]. Price HW. Dacryostenosis. J pediatr 1947;30: 302-5.

[8]. Crigler LW. The treatment of congenital dacryocystitis. JAMA 1923;81:23-4

[9]. Nucci P, et al. Conservative management of congenitalnasolacrimal duct obstruction. J PediatrOphthalmol Strabismus 1989; 26(1):39-43.

[10]. Nazullah Khan, Mohammad Naeem Khan, Sanaullah Jan, Shad Mohammad. Congenital Nasolacrimal Duct Obstruction: Presentation and Management. Pak J Ophthalmol 2006, Vol. 22 No. 2: 74-78

[11]. Cokkesser Y, Eerklioglu C, Er H. Comparative external versus endoscopic DCR: results of 115 patients. Otolaryngol Head Neck Surg 2000; 13: 488-91. 